\title{
Toz Metalurjisi Yöntemiyle Üretilen Karbon Nanotüp Takviyeli Mg Matrisli Kompozitlerin Aşınma Davranışlarının İncelenmesi
}

\section{An Investigation of Wear Behaviours of Mg Matrix Composites Reinforced Carbon Nanotube Produced by Powder Metallurgy Method}

\author{
Musa Yıldırım1 $^{\text {iD }}$, Dursun Özyürek ${ }^{2}$ iD \\ ${ }^{1}$ Karabük University Technology Faculty, Department of Industrial Design Eng. 78050 KARABÜK TURKEY \\ ${ }^{2}$ Karabük University Technology Faculty, Department of Manufacturing Eng. 78050 KARABÜK TURKEY
}

Başvuru/Received: 18/12/2021

Kabul / Accepted: 28/12/2021

Çevrimiçi Basım / Published Online: 31/12/2021

Son Versiyon/Final Version: 31/12/2021

\section{$\ddot{O} \mathbf{z}$}

Toz metalurjisi yöntemi ile AZ91-Karbon nanotüp takviyeli metal matrisli kompozitlerin üretimi ve aşınma davranışlarının incelendiği bu çalışmada, AZ91 Magnezyum alaşımına çok duvarlı karbon nanotüp ilave edilerek kompozit tozlar üretilmiştir. Üretilen kompozit tozlar soğuk preslenerek ön şekillendirilmiş arkasından $550{ }^{\circ} \mathrm{C}^{\prime} \mathrm{de} 1$ saat sinterlenmiştir. Sinterlenen kompozitlerin karakterizasyon çalışmaları yapılmışıı. Pin-on disk tipi aşınma cihazında $30 \mathrm{~N}$ yük altında üç farklı kayma mesafesinde aşınma testleri yapılmıştır. Yapılan çalışmalar sonucunda karbon nanotüp ilave edilen kompozitlerde sertlik değerinin arttığı en yüksek sertlik \%0,25 karbon nanotüp ilave edilen kompozitte elde edilmiştir. Ancak yapılan aşınma testleri sonucunda takviye elemanının yapı içerisinde homojen dağılmaması ve oluşan aglomerasyonlar sonucu ilave edilen takviye miktarıyla aşınmanın arttığı, ağırlık kaybındaki en yüksek değer \%2 karbon nanotüp takviyeli kompozitte elde edilmiştir.

\section{Anahtar Kelimeler}

"Mg matrisli kompozit, karbon nanotüp, toz metalürjisi, aşııma davranışları"

\begin{abstract}
In this study, production, and wear behaviours of AZ91-carbon nanotube reinforced metal matrix composites by powder metallurgy method were investigated. Composite powders were produced by multi wall carbon nanotube powders (four different amount) were added to AZ91 Mg. Produced composite powders were pre-formed by cold press then they were sintered at $550{ }^{\circ} \mathrm{C}$ for 1 hour. Sintered samples were characterized. Wear tests were done by pin-on disc type wear device under $30 \mathrm{~N}$ load with three sliding distances. At the end of the study, it was seen that hardness values were increased with increasing carbon nanotube amount. The maximum hardness value was measured in the $0.25 \%$ carbon nanotube added sample. However, according to wear test, the weight loss values were increased with increasing reinforcement amount due to non-homogenous distribution and occurred agglomeration of reinforcement. The maximum weight loss values were measured in added $2 \%$ sample.
\end{abstract}

Key Words

"Mg matrix composites, carbon nanotube, powder metallurgy, wear behaviours" 


\section{Giriş}

Metal matrisli kompozitler sahip olduğu yüksek elastikiyet modül oda sıcaklığında ve yüksek sıcaklıklarda göstermiş olduğu yüksek dayanım, sertlik ve aşınma direnci gibi özelliklerinden dolayı otomotiv, havacılık ve askeri alanda kullanımı gün geçtikçe artmaktadır (Kumar vd., 2011; Zhou vd., 2014; Tjong, 2013). Metal matrisli kompozitlerde matris malzemesi olarak tüm metaller kullanılabilmektedir. Ancak Al, Mg, Ti gibi yoğunluğu düşük malzemeler matris olarak tercih edilmektedir (Chawla, 2012). Mg düşük yoğunluğu, yüksek spesifik mukavemet iyi gürülttü ve titreşim sönümleme, çevre dostu ve geri dönüştürülebilirliği gibi özelliklere sahip olmasından dolayı otomotiv ve havacılık sektörü için umut vadeden bir metaldir. Ancak yüksek sıcaklıklarda kullanımı, zayıf aşınma ve korozyon direnci bu malzemelerin kullanımını sınırlamaktadır (Aydin \& Durgut, 2021; Jayabharathy \& Mathiazhagan, 2020). Düşük maliyet, kullanım kolaylığı, iyi mukavemet ve süneklik atmosferik korozyona karşı direnç gibi özelliklerinden dolayı $\mathrm{AZ} \mathrm{serisi} \mathrm{Mg}$ alaşımları içerisinde ön plana çıkmaktadır (Paramsothy vd., 2011). AZ91 alaşımı \%9 Al ve \%1 Zn içeren bir alaşım olup otomotiv sektöründe en yaygın kullanılan Mg alaşımları arasındadır (Wang vd., 2010). Zayıf mekanik özellikler ve düşük aşınma direncinden dolayı bu alaşım grubuna çeşitli takviyeler ilave edilerek Mg matrisli kompozitler üretilmektedir. Mg alaşımlarına ilave edilen en yaygın takviye elemanları $\mathrm{SiC}, \mathrm{Al}_{2} \mathrm{O}_{3}$, TiC gibi seramik yapılardır. Alaşım içerisine ilave edilen bu takviyeler ile çekme dayanımı, akma dayanımı, aşınma direnci gibi mekanik özellikler geliştirilmektedir. Bu takviye elemanları dışında günümüzde karbon nanotüp, grafen gibi nano boyutlara sahip takviye elemanları da kullanılmaktadır (Dey \& Pandey, 2015). Karbon nanotüpler keşfedildiği 1991 yılından beri araştırmacıların ilgisini oldukça çeken bir malzemedir. $150 \mathrm{GPa}$ çekme dayanımı $1 \mathrm{TPa}$ gibi yüksek elastikiyet modülüne sahip olması bu malzemelerin kompozit yapılarda takviye elemanı olarak kullanılması düşüncesiyle birçok çalışma yürütülmektedir (Li vd., 2009; Bakshi vd., 2010). Karbon nanotüp ilave edilerek üretilen kompozitlerde en yaygın görülen problem takviye elemanının yapı içerisinde homojen dağıtılamamasıdır. Nanopartiküller arasında bulunan yüksek Van der Waals etkileşimi bu malzemelerin ayrışmasını zorlaştırmaktadır. Geleneksel takviye elemanlarına göre oldukça fazla yüzey alanına sahip (yaklaşık $1000 \mathrm{~m}^{2} / \mathrm{g}$ ) olması bu malzemelerin aglomere olmasını sağlamaktadır (Li vd., 2009). KNT takviyeli metal matrisli kompozit üretilmesi için toz metalürjisi, çeşitli döküm yöntemleri infilitrasyon, termal sprey gibi çeşitli yöntemler kullanılmaktadır. Bu yöntemler arasında en yaygın olan toz metalürjisi yöntemidir. Bu yöntemde metal matris ile karbon nanotüp mekanik alaşımlama /mekanik öğütme yöntemleri ile karıştırılarak, ön şekillendirme ve sinterleme aşamalarıyla kompozitler üretilmektedir (Bakshi vd., 2010). Bu çalışmada AZ91 alaşımına farklı miktarlarda KNT ilave edilerek toz metalürjisi metoduyla kompozitler üretilerek bu kompozitlerin aşınma davranışları incelenmiştir.

\section{Materyal ve Metot}

Deneysel çalışmalarda matris malzemesi olarak Karabük Üniversitesi İmalat Mühendisliği'nde üretilen ve Tablo 1'de kimyasal bileşimi verilen gaz atomize AZ91 Magnezyum tozu (Dv $50155 \mu \mathrm{m}$ ) alaşımı kullanılmıştır. Takviye elemanı olarak yaklaşı 9,5 nm çapında $1,5 \mu \mathrm{m}$ uzunluğunda çok duvarlı karbon nanotüp kullanılmıştır.

Tablo 1. Matris malzemesi olarak kullanılan AZ91 alaşımının kimyasal bileşimi (Akkaş, 2017)

\begin{tabular}{lllll}
\hline & Al & Zn & Mn & Mg \\
AZ91 & 8,74 & 0,67 & 0,18 & Kalan \\
\hline
\end{tabular}

Kompozit numunelerin üretilmesi için AZ91 alaşımına ağırlıkça \%0,25, \%0,5, \%1, \%2 olmak üzere 4 farklı oranda karbon nanotüp ilave edilerek Fritch marka Pulverisite 6 mekanik alaşımlama /mekanik ögütme cihazında 400 rpm devirde 8 mm çelik bilye ile 10:1 bilye/toz oranı kullanılarak 2 saat öğütülerek kompozit tozlar üretilmiştir. Mekanik öğütme esnasında tozların ısınmasını önlemek için, 15 dakikalık öğ̈̈tme sonrası 10 dakika cihaz durdurulmuştur. Üretilen kompozit tozlar kalıp içerisine doldurularak $520 \mathrm{MPa}$ basınç altında pres yardımıyla ön şekillendirilerek $\varnothing 12 \times 7 \mathrm{~mm}$ boyutlarında silindirik numuneler elde edilmiştir. Ön şekillendirilen bu numuneler $550^{\circ} \mathrm{C}$ 'de 1 saat vakum altında sinterlenmiş̧ir. Sinterleme işlemleri sonrası elde edilen numuneler zımparalama ve parlatma gibi metalografik işlemler sonrası pikrik asit ile dağlanarak optik mikroskop ve taramalı elektron mikroskobu ile mikro yapı incelemeleri yapılmıştır. Sertlik ölçümleri Shimadzu marka mikro sertlik cihazında $0,5 \mathrm{~N}$ yük altında ilave edilen her oran için iki farklı numunenin 5 farklı bölgesinden ölçülerek ortalamaları hesaplanmıştır. Aşınma testleri pin-on disk tipi aşınma cihazında $1 \mathrm{~m} / \mathrm{s}$ kayma hızında $30 \mathrm{~N}$ yükte üç farklı kayma mesafesinde (500-1500 m) test edilmiştir. Aşınma testlerinde ağırlık kayıpları 1/10000 g hassasiyetine sahip terazide tartılmıştır. Aşınma testleri sonrası aşınma yüzeyleri SEM ile incelenmiştir.

\section{Sonuçlar ve Tartışma}

Matris ve farklı oranlarda karbon nanotüp ilave edilerek üretilen kompozitlerin optik mikroskop görüntüleri Şekil l'de verilmektedir. 


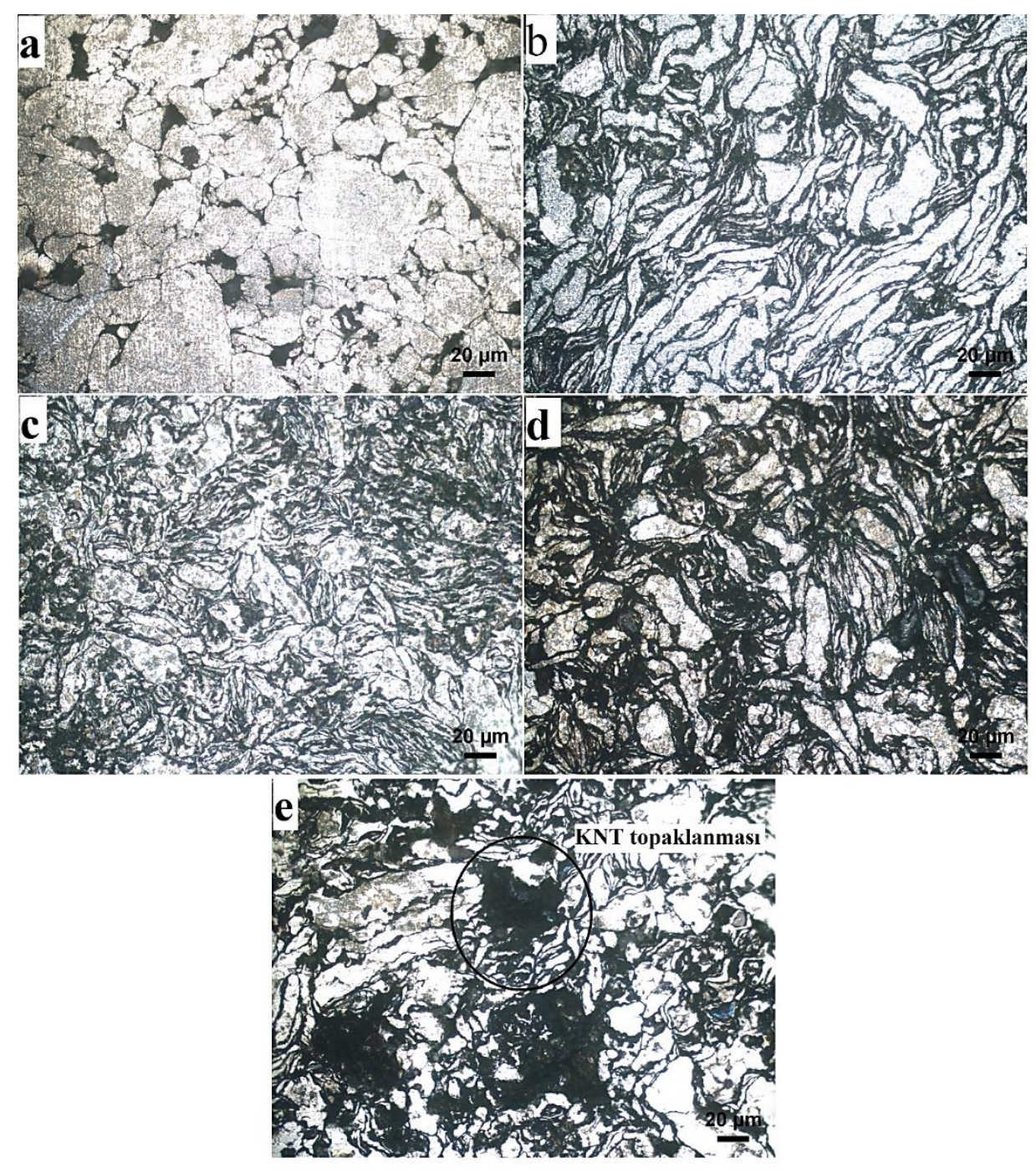

Şekil 1. Farklı oranlarda KNT ilave edilerek üretilen kompozitlerin mikro yapı görüntüleri; a) AZ91 alaşımı, b) \% 0,25 KNT-AZ91, c) $\%$ 0,5 KNT-AZ91 d) \% 1 KNT-AZ91 e) $\% 2$ KNT-AZ91

Şekil 1'de verilen mikro yapılar incelendiğinde AZ91 alaşımına ait tane yapıları açık renkte görülürken, alaşım içerisine KNT ilave edilmesiyle beraber tane sınırları arasında oluşan fazlar ve KNT aglomerasyonu koyu renkte görülmektedir. Alaşım içerisine $\% 0,25$ ve $\% 0,5 \mathrm{KNT}$ ilave edilerek üretilen kompozitlerde takviye elemanının yapı içerisinde homojene yakın bir dağılım sergilediği görülmektedir (b ve c). Şekil 1' de d ve e'de verilen mikro yapı resimlerine bakıldığında ise alaşıma ilave edilen KNT'lerin sadece tane sınırları arasında değil tane içerisinde ve belirli bölgelerde toplandığı ve aglomere olduğu net bir şekilde görülmektedir. Matris ve farklı oranlarda karbon nanotüp ilave edilerek üretilen kompozitlerin SEM görüntüleri Şekil 2'de verilmektedir. 


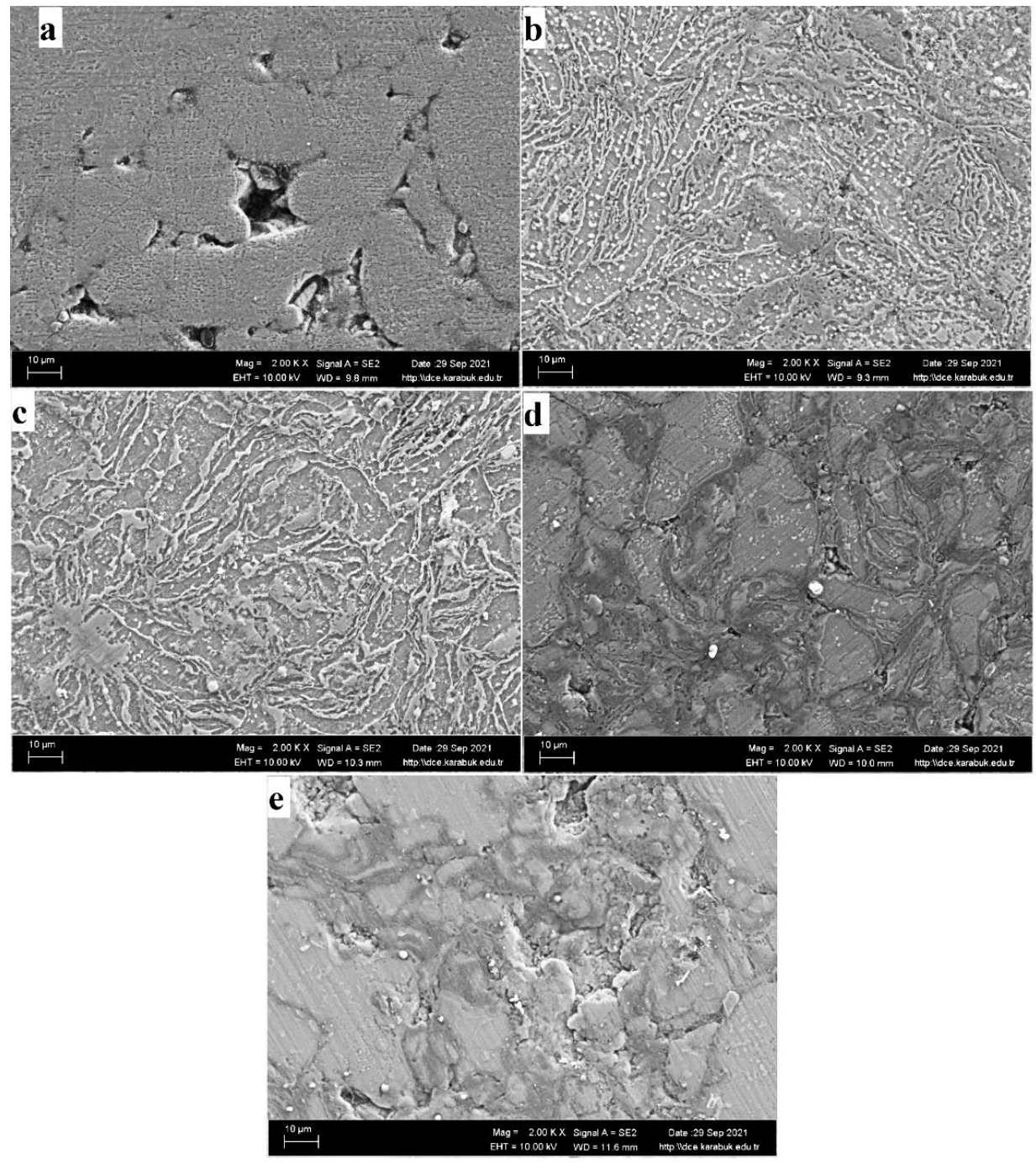

Şekil 2. Farklı oranlarda KNT ilave edilerek üretilen kompozitlerin SEM görüntüleri; a) AZ91 alaşımı, b) \% 0,25 KNT-AZ91, c)\% 0,5 KNT-AZ91 d) \% 1 KNT-AZ91 e) \% 2 KNT-AZ91

Şekil 2'de verilen yüksek büyütme SEM görüntüleri incelendiğinde matris yapısı olan a Mg yapısının dışında özellikle KNT ilave edilerek üretilen kompozitlerde tane yüzeylerinde ve tane sınırlarında ağımsı bir yapı görülmektedir. Görülen bu yapının tespiti için alınan EDS görüntüleri Şekil 3’te verilmektedir. 


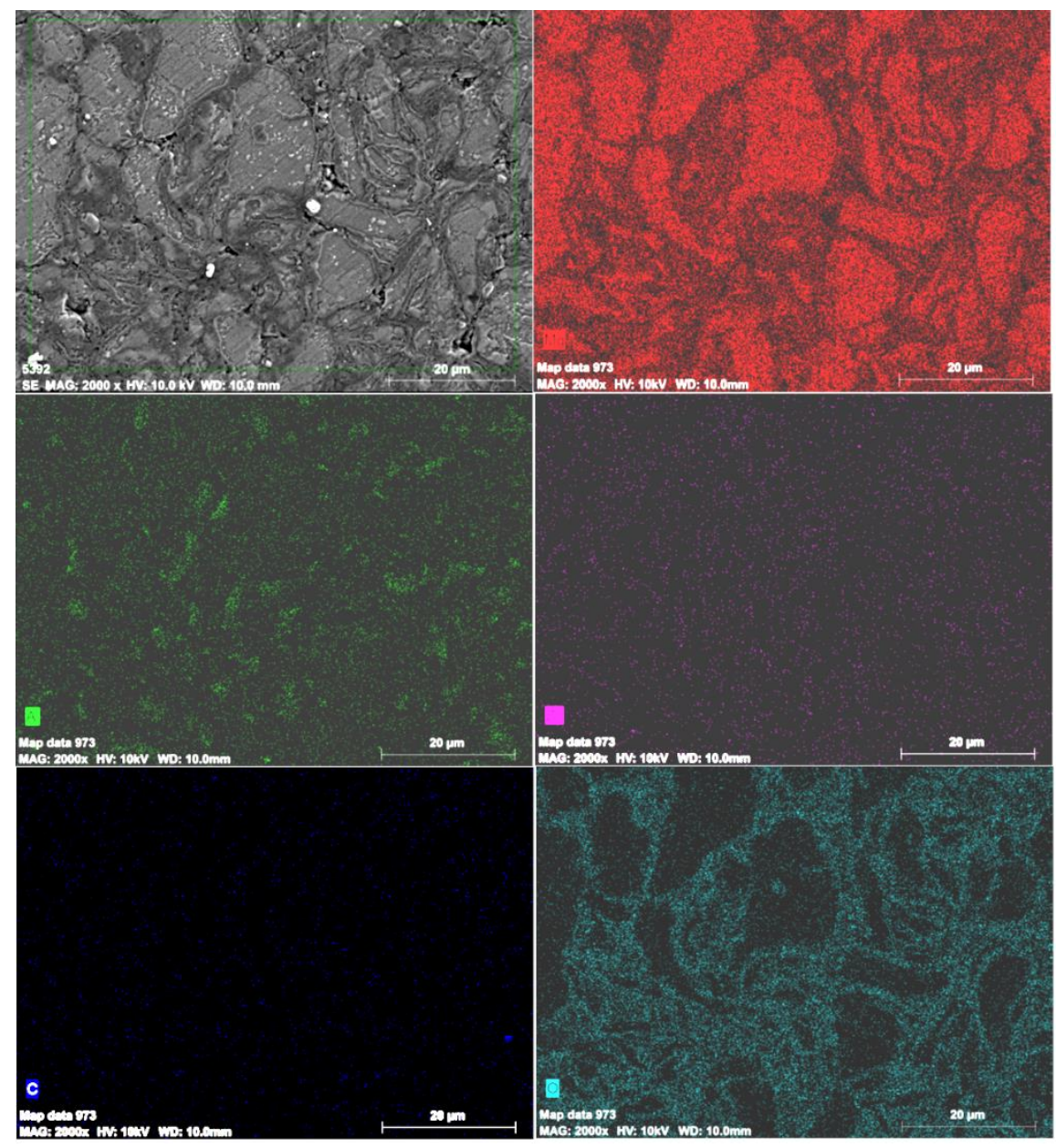

Şekil 3. \% 1 KNT ilave edilen kompozitin EDS mapping görüntüsü

Şekil 3'de verilen EDS mapping görüntüleri incelendiğinde \% $1 \mathrm{KNT}$ ilave edilen kompozit yapıda matris malzemenin Mg olduğu alaşım içerisinde bulunan Al, Zn gibi elementlerin yapıda homojene yakın bir dağılım sergilediği görülmektedir. Ancak Şekil 1'de verilen optik mikroskop görüntüsünde görülen karbon nanotüp aglomerasyonu EDS mapping görüntüsünde görülememişsir. Tane sınırları boyunca oluşan ağ yapısının oksijence zengin olduğu bu görüntüden anlaşılmaktadır. Bu durumun daha net tespitinin yapılabilmesi amacıyla alınan EDS nokta analiz sonucu Şekil 4'te verilmektedir.
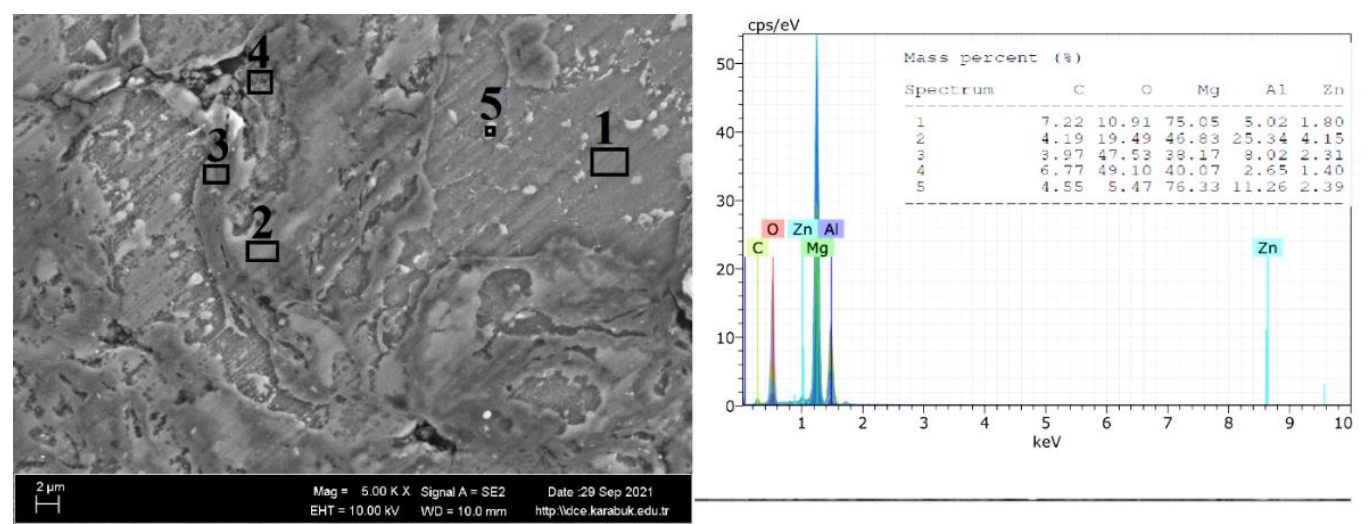

Şekil 4. \%1 KNT ilave edilen kompozitin EDS nokta analiz görüntüsü

Şekil 4'te verilen EDX nokta analizinde 1 numaralı bölgenin Mg'ce zengin bölge olan $\alpha$ Mg matris yapı olduğu 2 numaralı bölgenin $\mathrm{Mg}$ ve Al'ca zengin olması nedeniyle AZ91 alaşımında bulunan $\beta$ fazı olduğu $\left(\mathrm{Mg}_{17} \mathrm{Al}_{12}\right) 3$ ve 4 numaralı bölgenin oksijen ve $\mathrm{Mg}$ oranlarının yüksek olmasından dolayı sinterleme sırasında oluşan $\mathrm{MgO}$ fazı olabileceği düşünülmektedir. $\mathrm{Mg}$ 'un oksijen ile afinetisinin yüksek olması ve oksidasyona çok eğimli olması yüzeyde $\mathrm{MgO}$ yapıların oluşmasını sağlamaktadır. Ayrıca yapılan literatür 
incelemelerinde AZ91 alaşımına karbon nanotüp ilave edilmesi sonucu mikro yapıda yukarıda belirtilen fazların oluştuğu birçok çalışmada rapor edilmektedir (Islak, vd., 2017; Zhao vd., 2016; Turan vd., 2020; Mindivan vd., 2014).

Matris olarak kullanılan AZ91 ve farklı oranlarda karbon nanotüp ilave edilerek üretilen kompozitlerin sertlik sonuçları Şekil 5'te grafik halinde verilmektedir.

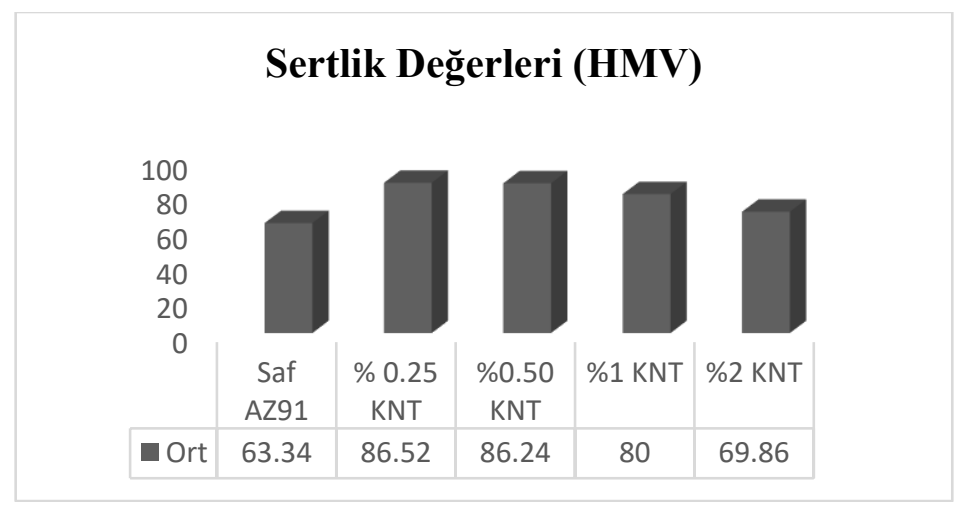

Şekil 5. Matris ve farklı oranlarda KNT içerek kompozitlerin sertlik sonuçları

Yapılan sertlik ölçümleri sonucunda KNT ilave edilen kompozitlerde sertlik artışı görülmüştür. En yüksek sertlik değeri \%0,25 oranında KNT ilave edilen kompozitte elde edilirken alaşım içerisine ilave edilen takviye oranı arttıkça sertlikte düşüş meydana gelmektedir. En düşük sertlik değeri \%2 KNT ilave edilen kompozitte görülmüştür. Metal matrisli parçacık takviyeli kompozitlerde mekanik özellikleri etkileyen çeşitli faktörler bulunmaktadır. Matris ve takviye malzemesinin çeşidi, takviye elemanının boyutu matris ve takviye ara yüzey bağı, takviye fazının yapı içerisindeki homojen dağılımı bu faktörler kompozitin mekanik özelliklerini doğrudan etkiler. Matris ve takviye fazı arasında oluşan ara yüzey bağının kuvvetli olması sayesinde matrise binen yükün takviye elemanına aktarılması ile sertlik değerlerinde artış yaşanır. Ayrıca matris içerisine ilave edilen takviye elemanları tane sınır bölgelerine yerleşerek malzemenin tane büyümesi engellenir. Böylelikle dislokasyon hareketleri sınırlanarak mukavemet artışı gerçekleşir. Metal matrisli nanokompozitlerde takviye elemanının boyutunun küçük olması ile Orowan mekanizması sayesinde dayanım artmaktadır (Abazari vd., 2020). Nano boyuttaki malzemelerin yüzey enerjisinin yüksek olmasından dolayı ile kompozite ilave edilen nano takviyeler aglomere olmakta ve yapıda homojen dağıtılamamaktadır. Böylelikle kompozitlerde beklenen büyük mekanik artış gerçekleşmemektedir. Matris olarak kullanılan AZ91 ve farklı oranlarda karbon nanotüp eklenerek üretilen malzemelerin aşınma test sonuçları Şekil 6' da grafik halinde verilmektedir.

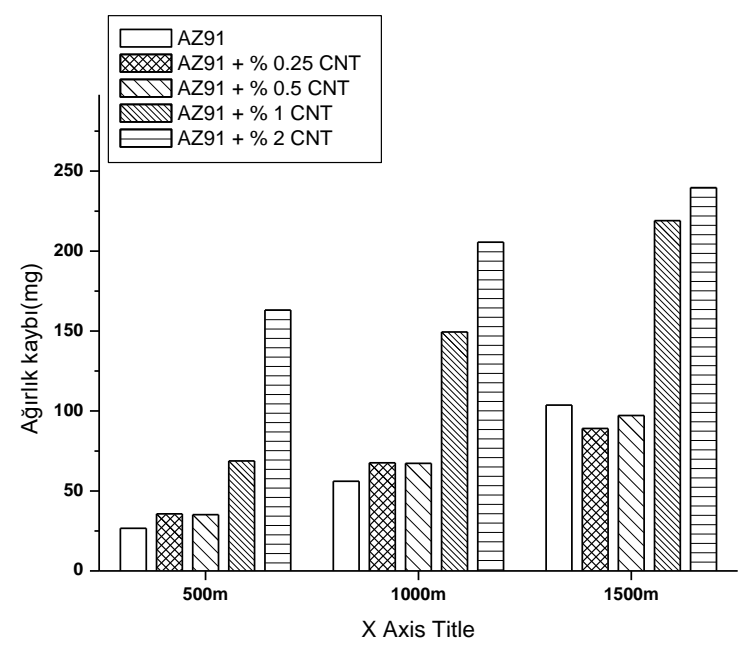

Şekil 6. Matris ve farklı oranlarda KNT içeren kompozitlerin aşınma testi ağırlık kaybı sonuçları

Yapılan aşınma testleri sonucunda 500 ve 1000 metre kayma mesafesinde en düşük ağılık kaybı AZ91 alaşımında görülürken 1500 m kayma mesafesinde en düşük ağırlık kaybı \%0,25 KNT ilave edilen kompozitte görülmüştür. Tüm kayma mesafelerinde en yüksek ağırlık kaybı ise \%2 KNT ilave edilen kompozitte görülmüştür. Yapılan aşınma testleri sonucu, ağırlık kaybındaki en yüksek değerin, en düşük sertliğe sahip malzemede (AZ91 alaşımında) olması beklenmektedir. Ancak Şekil 1'de verilen optik mikroskop görüntüsünden de anlaşılacağı gibi matris içerisindeki KNT miktarı arttıkça oluşan aglomerasyon sonucu matris ile takviye elemanı 
arasında yeterli ara yüzey bağının kurulamaması, sinterleme sırasında aglomere olan KNT'lerin yeterli ısıya maruz kalamaması ve aşınma sırasında oluşan deformasyon sonucu bu bölgelerden kütlesel kopmaların meydana gelmesinden dolayı ağırlık kaybı daha fazla olmaktadır. Bu durumun daha net tespit edilmesi amacıyla aşınma yüzeylerinden alınan SEM görüntüleri Şekil 7'de gösterilmektedir.

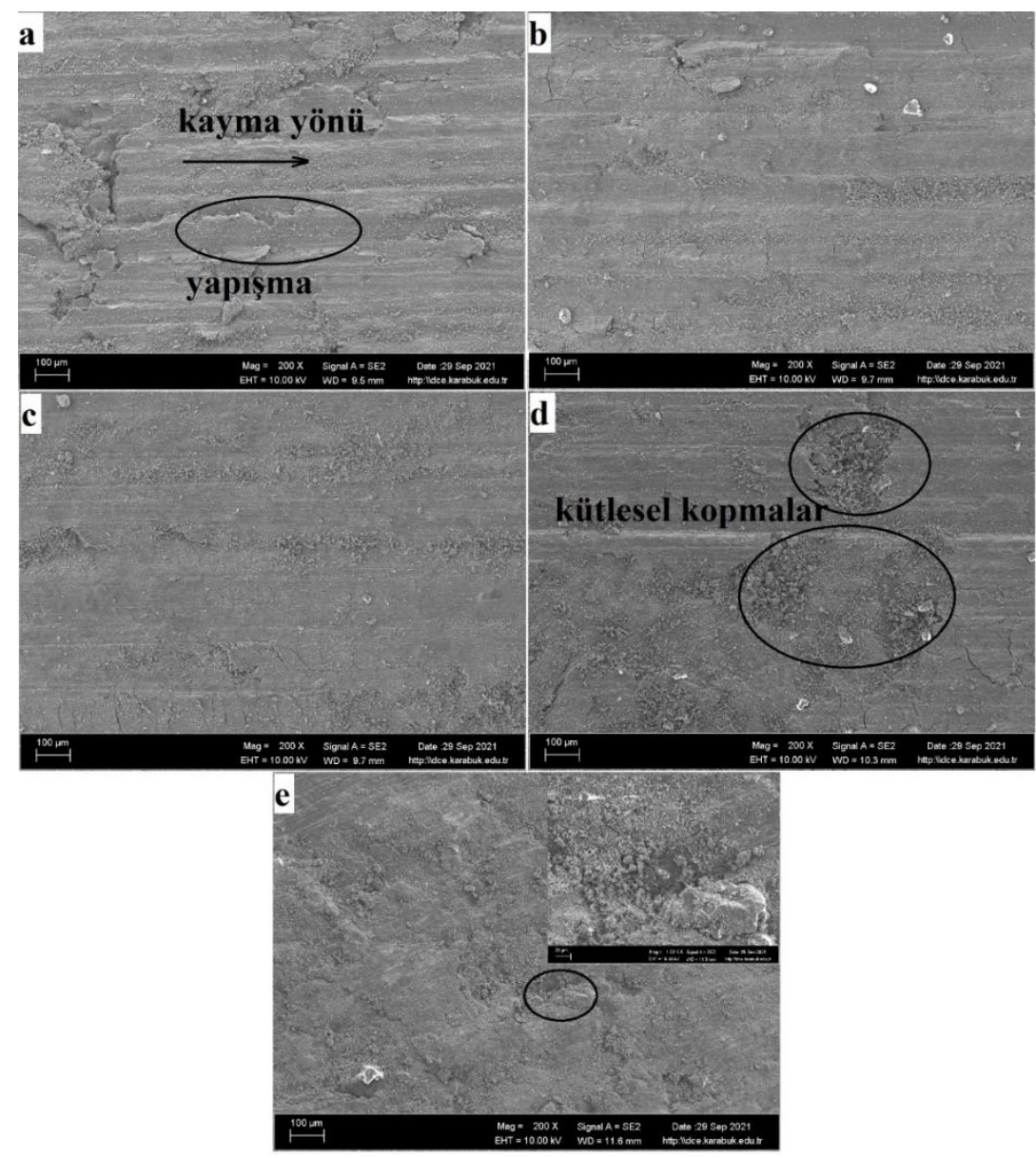

Şekil 7. Farklı oranlarda KNT ilave edilerek üretilen kompozitlerin aşınma SEM görüntüleri; a) AZ91 alaşımı, b) \% 0,25 KNTAZ91, c) \% 0,5 KNT-AZ91 d) \% 1 KNT-AZ91 e) \% 2 KNT-AZ91

Şekil 7'de verilen aşınma yüzey SEM görüntüleri incelendiğinde kayma işlemi sırasında meydana gelen plastik deformasyon etkisi ile kayma çizgilerinin oluştuğu görülmektedir. Ayrıca bazı bölgelerde (Şekil 7a) deformasyon sonucu kopan parçaların yüzeye tekrar yapıştığı görülmektedir. KNT oranı \%1 ve \%2 olan numunelerin aşınma yüzey SEM görüntülerine bakıldığında ise (Şekil 7d ve 7e) aşınma sırasında deformasyonla beraber büyük kütlesel kopmaların oluştuğu görülmektedir. Şekil 1'de verilen optik mikroskop görüntülerinde ifade edildiği gibi yapı içerisinde homojen dağıtılamayan, aglomere olan nanoparçacıklar ile matris arasında yeterli ara yüzey bağının oluşamaması kayma sırasında oluşan plastik deformasyon ile kopmalar gerçekleşmektedir. Şekil 6'da verilen ağırlık kaybı sonuçları ile aşınma yüzey SEM görüntüleri birbirini doğrulamaktadır. Genel olarak aşınma yüzey SEM görüntüleri incelendiğinde hem adhesive (Şekil 7a) hem de abrsif aşınma mekanizmalarının etkin olduğu söylenebilir.

\section{Sonuçlar}

Yapılan bu çalışma ile elde edilen sonuçlar aşağıda maddeler halinde verilmektedir.

- Mekanik ögütme yöntemi ile AZ91 alaşımına KNT ilave edilerek Mg matisli kompozit üretilmiştir.

- Üretilen kompozitlerde KNT miktarı arttıkça takviye fazının yapıda homojen dağıtılamadığı takviye fazının belirli bölgelerde topaklandığı tespit edilmiştir.

- Alaşıma ilave edilen KNT ile sertliğin arttığı, en yüksek sertlik değerinin AZ91 alaşımına \%0,25 KNT ilave edilen kompozitte görülürken KNT oranı arttıkça sertliğin düştüğü görülmüştür.

- Aşınma test sonuçlarına göre \%1'den daha fazla KNT ilave edilen kompozitlerde ağırlık kaybının oldukça arttığı görülmüştür. 


\section{Referanslar}

Abazari, S., Shamsipur, A., Bakhsheshi-Rad, H. R., Ismail, A. F., Sharif, S., Razzaghi, M., ... \& Berto, F. (2020). Carbon nanotubes (CNTs)-reinforced magnesium-based matrix composites: A comprehensive review. Materials, 13(19), 4421. https://doi.org/10.3390/ma13194421

Akkaş, M (2017) Gaz atomizasyon yöntemi ile AZ91 tozu üretimi ve karakterizasyonu, Doktora Tezi, Karabük Üniversitesi Fen Bilimleri Enstitüsü, Karabük

Aydin, F., \& Durgut, R. (2021). Estimation of wear performance of AZ91 alloy under dry sliding conditions using machine learning methods. Transactions of Nonferrous Metals Society of China, 31(1), 125-137. https://doi.org/10.1016/S1003-6326(20)65482-6

Bakshi, S. R., Lahiri, D., \& Agarwal, A. (2010). Carbon nanotube reinforced metal matrix composites-a review. International materials reviews, 55(1), 41-64. https://doi.org/10.1179/095066009X12572530170543

Chawla K.K. (2012). Metal Matrix Composites. In: Composite Materials. Springer, New York, NY. https://doi.org/10.1007/978-0-38774365-3_6

Dey, A., \& Pandey, K. M. (2015). Magnesium Metal Matrix Composites-A Review. Reviews on Advanced Materials Science, 42(1).

Islak, S., Küçük, Ö., Eski, Ö., Özorak, C., \& Akkaş, M. (2017). The Effect of CNT Content and Sintering Temperature on Some Properties of CNT-reinforced MgAl Composites. Science of Sintering, 49(4). https://doi.org/10.2298/SOS1704347I

Jayabharathy, S., \& Mathiazhagan, P. (2020). Investigation of mechanical and wear behaviour of AZ91 magnesium matrix hybrid composite with TiO2/graphene. Materials Today: Proceedings, 27, 2394-2397. https://doi.org/10.1016/j.matpr.2019.09.142

Kumar, G. V., Rao, C. S. P., \& Selvaraj, N. (2011). Mechanical and tribological behavior of particulate reinforced aluminum metal matrix composites-a review. Journal of minerals and materials characterization and engineering, 10(01), 59.

Li, Q., Viereckl, A., Rottmair, C. A., \& Singer, R. F. (2009). Improved processing of carbon nanotube/magnesium alloy composites. Composites Science and Technology, 69(7-8), 1193-1199. https://doi.org/10.1016/j.compscitech.2009.02.020

Mindivan, H., Efe, A., Kosatepe, A. H., \& Kayali, E. S. (2014). Fabrication and characterization of carbon nanotube reinforced magnesium matrix composites. Applied surface science, 318, 234-243. https://doi.org/10.1016/j.apsusc.2014.04.127

Paramsothy, M., Chan, J., Kwok, R., \& Gupta, M. (2011). Enhanced mechanical response of hybrid alloy AZ31/AZ91 based on the addition of Si3N4 nanoparticles. Materials Science and Engineering: A, 528(21), 6545-6551. https://doi.org/10.1016/j.msea.2011.05.003

Tjong, S. C. (2013). Recent progress in the development and properties of novel metal matrix nanocomposites reinforced with carbon nanotubes and graphene nanosheets. Materials Science and Engineering: R: Reports, 74(10), 281-350. https://doi.org/10.1016/j.mser.2013.08.001

Turan, M. E., Zengin, H., \& Sun, Y. (2020). Dry sliding wear behavior of (MWCNT+ GNPs) reinforced AZ91 magnesium matrix hybrid composites. Metals and Materials International, 26(4), 541-550. https://doi.org/10.1007/s12540-019-00338-8

Wang, L., Zhang, B. P., \& Shinohara, T. (2010). Corrosion behavior of AZ91 magnesium alloy in dilute NaCl solutions. Materials \& Design, 31(2), 857-863. https://doi.org/10.1016/j.matdes.2009.07.049

Zhao, F. Z., Feng, X. H., \& Yang, Y. S. (2016). Microstructure and mechanical properties of CNT-reinforced AZ91D composites fabricated by ultrasonic processing. Acta Metallurgica Sinica (English Letters), 29(7), 652-660. https://doi.org/10.1007/s40195-0160438-6

Zhou, D., Qiu, F., Wang, H., \& Jiang, Q. (2014). Manufacture of nano-sized particle-reinforced metal matrix composites: a review. Acta Metallurgica Sinica (English Letters), 27(5), 798-805. https://doi.org/10.1007/s40195-014-0154-Z 